Jurnal Politico Vol. 2 September 2018

Halaman 219-235. ISSN: p; 1829-6696, e:2549-4716

Web jurnal online; jurnal.unmuhjember.ac.id

Edhi Siswanto; Ika Herawati

UPAYA DINAS PERPUSTAKAAN DALAM MENINGKATKAN MUTU PELAYANAN

(studi Dinas Perpustakaan dan Kearsipan Kabupaten Jember)

\title{
UPAYA DINAS PERPUSTAKAAN DALAM MENINGKATKAN MUTU PELAYANAN \\ (studi Dinas Perpustakaan dan Kearsipan Kabupaten Jember)
}

\author{
Edhi Siswanto; Ika Herawati \\ Program Studi Ilmu Pemerintahan \\ Fakultas Ilmu Sosial dan Ilmu Politik Universitas Muhammadiyah Jember \\ Email: edhisiswanto@unmuhjember.ac.id
}

Received: 12 Agustus 2018, Revised: 29 Agustus 2018, Accepted: 30 Agustus 2018

\begin{abstract}
This study aims to find out the efforts of Library Office in improving the quality of service (study of the Library and Archives Office of Jember Regency). This type of research uses qualitative research with a descriptive approach. Data sources are obtained from primary and secondary data. Collecting data through observation, interviews and documentation. The analysis uses data analysis of interactive models which include, Data Collection, Data Reduction, Data Presentation and Conclusing Drawing / Verification. The results showed that there were several efforts of the Library Service in improving the quality of service which could be measured using management theory with 4 factors namely Planning, Organizing, Actuating, Controlling but these efforts had not been maximized due to constraints on the quality of human resources is minimal
\end{abstract}

Keywords: Effort, Library, Reading Interest, Service Quality 
Jurnal Politico Vol. 2 September 2018

Halaman 219-235. ISSN: p; 1829-6696, e:2549-4716

Web jurnal online; jurnal.unmuhjember.ac.id

Edhi Siswanto; Ika Herawati

UPAYA DINAS PERPUSTAKAAN DALAM MENINGKATKAN MUTU PELAYANAN

(studi Dinas Perpustakaan dan Kearsipan Kabupaten Jember)

\section{PENDAHULUAN}

Perpustakaan merupakan institusi untuk mengelola literatur karya ilmiah, cetak, rekam secara profesional menggunakan cara-cara yang sudah dibakukan untuk memenuhi kebutuhan penelitian, rujukan, pendidikan, informasi, serta rekreasi bagi pemustaka. Institusi ini ada beberapa jenis tergantung wilayah dan kelompok pembaca yang dilayaninya. Fungsi dan status masing-masing perpustakaan telah diatur dengan undang-undang maupun peraturan lain di bawahnya. Indonesia masih belum memiliki perpustakaan yang dapat bersaing dengan negara berkembang lainnya. Selama ini perpustakaan masih memiliki pelayanan yang kurang maksimal, masih minimnya program pemberdayaan masyarakat. Hal tersebut menyebabkan perpustakaan Indonesia masih sangat jauh dengan negara berkembang lainnya.

Perpustakaan merupakan tempat penyediaan buku bahan bacaan. Perpustakaan memiliki tujuan khusus sebagai pemberi layanan informasi untuk kegiatan belajar, dan riset enelitian. Perpustakaan umum juga merupakan fasilistas dari pemerintah namun masih banyak masyarakat yang masih belum memanfaatkan fasilistas tersebut sebagai sarana pembelajaran. Masih minimmnya budaya membaca, buku hanya di anggap kebutuhan sekunder Sehingga perpustakaan saat ini secara umum tidak berfungsi secara optimal, masyarakat juga tidak punya anggaran membeli buku, terbitan terkala, majalah, koran, dan jurnal. Dalam hal ini Dinas Perpustakaan berperan penting sebagai alat penunjang kemampuan dan keterampilan bagi masyarakat.

Dalam rangka mengembangkan dinas perpustakaan dan kearsipan daerah, pemerintah kabupaten Jember mengesahkan Perbup. No.52 Th. 2016 mengenai kedudukan, susunan organisasi, tugas, fungsi, tata kerja Dinas Perpustakaan dan Kearsipan Kabupaten Jember dengan bertujuan menjadikan perpustakaan yang berkualitas dan berfungsi secara optimal. Oleh karena itu dinas perpustakaan dan kearsipan Kabupaten Jember terus berupaya untuk meningkatkan minat baca di kalangan pelajar. Dari uraian tersebut, penulis meneliti dengan judul "Upaya Dinas 
Jurnal Politico Vol. 2 September 2018

Halaman 219-235. ISSN: p; 1829-6696, e:2549-4716

Web jurnal online; jurnal.unmuhjember.ac.id

Edhi Siswanto; Ika Herawati

UPAYA DINAS PERPUSTAKAAN DALAM MENINGKATKAN MUTU PELAYANAN

(studi Dinas Perpustakaan dan Kearsipan Kabupaten Jember)

Perpustakaan dalam Meningkatkan Mutu layanan (Studi kasus pada Dinas Perpustakaan dan Kearsipan Daerah Kabupaten Jember).

\subsection{Rumusan Masalah}

Rumusan masalah dalam penelitian sebagaimana berikut::

1. Bagaimanakah upaya Dinas Perpustakaan dalam meningkatkan mutu layanan?

2. Hambatan apa yang di hadapi Dinas Perpustakaan dalam meningkatkan mutu layanan?

\subsection{Tujuan Penelitian}

Tujuan dari penelitian sebagaimana berikut:

1. Mengetahui upaya Dinas Perustakaan dalam meningkatkan mutu layanan.

2. Mengetahui hambatan yang di hadapi Dinas Perpustakaan dalam upaya meningkatkan mutu layanan.

\subsection{Manfaat penelitian}

\section{4.1 Manfaat Praktis}

Diharapkan dari hasil penelitian nantinya menjadi saran serta masukan bagi pemegang kebijakan dan pengelola perpustakaan dalam upaya meningkatkan layanannya terhadap masyarakat, selanjutnya sebagai masukan bagi perpustakaan daerah Kabupaten Jember dalam menentukan skala prioritas dalam mengambil kebijakan.

\subsubsection{Manfaat Teoritis}

Diharapkan dari penelitian dapat menjadi referensi dan bahan pertimbangan bagi penelitian selanjutnya.

\subsubsection{Manfaat Bagi Peneliti}

Diharapkan dari penelitian ini dapat bermanfaat untuk meningkatkan pengetahuan peneliti sebagai bahan pemahaman dan pembelajaran di lapang. 
Jurnal Politico Vol. 2 September 2018

Halaman 219-235. ISSN: p; 1829-6696, e:2549-4716

Web jurnal online; jurnal.unmuhjember.ac.id

Edhi Siswanto; Ika Herawati

UPAYA DINAS PERPUSTAKAAN DALAM MENINGKATKAN MUTU PELAYANAN

(studi Dinas Perpustakaan dan Kearsipan Kabupaten Jember)

\section{TINJAUAN PUSTAKA}

\subsection{Pengertian Upaya}

Upaya adalah usaha atau ikhtiar mencapai suatu maksud/tujuan, untuk menuntaskan permasalahan, mencari alternative jalan keluar/solusi; mengupayakan adalah mengusahakan/ mengikhtiarkan/melakukan sesuatu untuk mencari jalan keluar/solusi. Upaya dilakukan mencapai suatu maksud/tujuan, memecahkan masalah/ persoalan, serta mencari jalan sousi/keluar dari permasalahan.

\subsection{Pengertian Pengembangan}

Pengembangan artinya proses menterjemahkkan atau menjabarkan spesifikasi rancangan menjadi bentuk fitur fisik (Seels \& Richey, Alim sumarno, 2012). Tujuan dari Pengembangan adalah untuk menghasilkan produk temuan uji lapangan.

\subsection{Program Pengembangan Perpustakaan}

Program adalah suatu perencanaan, persiapan, desain atau rancangan. Program pengembangan pada perpustakaan menjadi sangat penting karena menyangkut kebijakan-kebijakan yang dapat membuat sebuah perpustakaan berkembang.

\subsection{Pengertian Manajemen}

Manajemen merupakan seni kemampuan untuk dapat menyelesaikan suatu pekerjaan melalui orang lain (Follet yang dikutip oleh Wijayanti 2008: 1) mengartikan. Manajemen merupakan proses perencanaan, pengorganisasian, pengarahan, serta suatu pengawasan usaha anggota organisasi serta pemanfaatan sumber daya, SDM organisasi untuk mencapai tujuan organisasi.(Stoner yang dikutip oleh Wijayanti 2008: 1).

\subsection{Pengertian Pelayanan}

Pelayanan merupakan "service”. A.S Moenir (2002:26-27) menjelaskan bahwa "pelayanan sebagai kegiatan yang di lakukan oleh seorang atau sekelompok orang dengan landasan tertentu dimana tingkat pemuasannya hanya dapat di rasakan oleh orang yang melayani atau di layani, tergantung kepada kemampuan penyedia jasa dalam 
Jurnal Politico Vol. 2 September 2018

Halaman 219-235. ISSN: p; 1829-6696, e:2549-4716

Web jurnal online; jurnal.unmuhjember.ac.id

Edhi Siswanto; Ika Herawati

UPAYA DINAS PERPUSTAKAAN DALAM MENINGKATKAN MUTU PELAYANAN

(studi Dinas Perpustakaan dan Kearsipan Kabupaten Jember)

memenuhi harapan pengguna." Sedangkan Publik yaitu "sejumlah manusia yang memiliki kebersamaan berfikir, perasaan, harapan, sikap dan tindakan yang benar dan baik berdasarkan nilai-nilai norma yang mereka miliki”. (Inu Kencana Syafi'ie dkk 199:18)

\subsection{Konsep Perpustakaan}

Perpustakaan merupakan suatu ruang/ tempat/ gedung disediakan sebagai pemeliharaan, penggunaan koleksi buku serta hal lainnya. Perpustakaan merupakan ruangan, atau bagian dari gedung. ataupun gedung itu sendiri yang digunakan untuk menyimpan buku dan terbitan lainnya dan disimpan menurut tata susunan tertentu serta digunakan pembaca, bukan untuk dijual (Sulistyo-Basuki 1991:3). Buku dan terbitan lainnya termasuk semua bahan cetak, jurnal, buku, majalah, prosiding, laporan, pamflet, lembaran musik, berbagai karya musik, manuskrip (naskah), berbagai karya media audiovisual seperti filem, slid (slide), kaset, piringan hitam, bentuk mikro seperti mikrofilm, mikrofis, dan mikroburam/microopaque.

\section{METODE PENELITIAN}

\subsection{Jenis Penelitian}

Penelitian yang dilakukan menggunakan metode kualitatif deskriptif. Metodologi kualitatif menghasilkan data deskriptif berupa kata tertulis atau lisan dari orang dan perilaku yang dapat di amati (Bogdan dan Taylor 1975 dikutip oleh Moleong 2007:4).

\subsection{Lokasi dan Waktu Penelitian}

Adapun penelitian ini dilaksanakan di Dinas Perpustakaan dan Kearsipan Daerah di J1. Letjen Panjaitan No.49, Sumbersari Kabupaten Jember. Penelitian di laksanakan selama 2 bulan Penelitian dilakukan dalam upaya meningkatkan minat baca pada masyarakat. Sedangkan alasan lain yang mendasari lokasi dekat tempat tinggal peneliti dan mudah untuk langsung terjun dalam melakukan penelitian dan mudah untuk mengumpulkan informasi dan data yang mendukung kegiatan. 
Jurnal Politico Vol. 2 September 2018

Halaman 219-235. ISSN: p; 1829-6696, e:2549-4716

Web jurnal online; jurnal.unmuhjember.ac.id

Edhi Siswanto; Ika Herawati

UPAYA DINAS PERPUSTAKAAN DALAM MENINGKATKAN MUTU PELAYANAN

(studi Dinas Perpustakaan dan Kearsipan Kabupaten Jember)

\subsection{Sumber Data}

Sumber data diperoleh dan relevan dengan permasalahan meliputi data primer data sekunder.

1. Data Primer berasal dari data yang dikumpulkan secara langsung dari obyeknya, atau informan atau data yang belum jadi, diperoleh langsung dari individu yang diselidiki dari informan di lapangan.

2. Data Sekunder berasal dari sumber data yang tidak dibatasi ruang waktu dimana jenis informasi atau data sudah ada dan tersedia, sehingga peneliti dapat tinggal mengambil, mengumpulkan, serta mengklasifikasikan dan mereduksi data.

\subsection{Informan Penelitian}

Adapun inforan dalam penelitian ini dipilih menggunakan teknik penentuan informan yang digunakan yaitu Purposive sampling dengan menunjuk langsung informan yang akan dijadikan narasumber pemberi data dan informasi.

\subsection{Teknik Pengumpulan Data}

a. Metode Observasi

Observasi dilakukan dengan mengamati, mencatat, fakta/ fenomena tidak hanya pengamatan yang dilakukan peneliti, baik langsung tetapi dilakukan secara tidak langsung. Observasi merupakan pengamatan untuk mendapatkan data dari fenomena yang diamati secara langsung maupun tidak langsung. Observasi atau pengamatan, peneliti bereran sebagai pengamat dan juga fungsi pengamatan. Dengan kata lain pengamat hanya melakukan satu fungsi yang dalam hal ini hanya mengadakan pengamatan saja.

b. Wawancara

Interview dilakukan oleh peneliti dengan berpedoman pada pedoman wawancara yang berisi hal-hal yang akan digali dan ditanyakan agar wawancara tidak menyimpang dari tujuan. Pengamatan peneliti melalui penggunaan 
Jurnal Politico Vol. 2 September 2018

Halaman 219-235. ISSN: p; 1829-6696, e:2549-4716

Web jurnal online; jurnal.unmuhjember.ac.id

Edhi Siswanto; Ika Herawati

UPAYA DINAS PERPUSTAKAAN DALAM MENINGKATKAN MUTU PELAYANAN

(studi Dinas Perpustakaan dan Kearsipan Kabupaten Jember)

pancaindra." Dengan metode pengumpulan data ini, peneliti akan mengamati langsung bagaimana atau seperti apa masalah yang berkaitan dengan penelitian terjadi di lokasi.

c. Dokumentasi

Menurut Suharsimi Arikunto (2001: 36) yang memberikan definisi tentang dokumenter yaitu dari asal kata "dokumen" yang artinya barang-barang tertulis, artinya dalam melaksanakan metode dokumentasi peneliti menyelidiki bendabenda tertulis. Dengan pendapat dari Suharsimi Arikunto tersebut bahwa dokumentasi yang di pakai dalam penelitian adalah mempelajari dan mencatat data-data yang sudah didokumentasikan seperti laporan, arsip, laporan kegiatan atau dokumen- dokumen yang diperlukan dalam pengumpulan data.

\subsection{Teknik Analisa Data}

Analisa data adalah proses mengatur urutan data mengorganisasikan dalam bentuk pola, kategori dan satuan uraian data (Potton dikutip oleh Moleong 2000:108). Analisa data kualitatif menurut Bogdan dan Biklen, dikutip oleh Moleong merupakan upaya yang dilakukan melalui jalan bekerja dengan data, mengorganisasikan data, memilah-milahnya menjadi satuan yang dapat dikelola, mensitensiskannya mencari dan menemukan pola, menemukan apa yang penting dan apa yang dipelajari, dan memutuskan apa yang dapat diceritakan kepada orang lain.

\subsection{Teknik Keabsahan Data}

Data yang tidak benar menyebabkan kesimpulan menjadi tidak benar, demikian juga sebaliknya, data yang sah dan benar akan menghasilkan kesimpulan penelitian yang benar juga. Alwasilah dalam Bachri (2010:54) menjelaskan bahwa "tantangan bagi semua jenis penelitian pada akhirnya adalah terwujudnya produksi ilmu pengetahuan yang valid, sahih, benar, dan beretika. 
Jurnal Politico Vol. 2 September 2018

Halaman 219-235. ISSN: p; 1829-6696, e:2549-4716

Web jurnal online; jurnal.unmuhjember.ac.id

Edhi Siswanto; Ika Herawati

UPAYA DINAS PERPUSTAKAAN DALAM MENINGKATKAN MUTU PELAYANAN

(studi Dinas Perpustakaan dan Kearsipan Kabupaten Jember)

\section{HASIL PENELITIAN}

\section{A. Deskripsi hasil penelitian Upaya Dinas Perpustakaan dalam meningkatkan mutu Pelyanan di Kabupaten Jember}

Seperti yang di paparkan sebelumnya maka Upaya Dinas Perpustakaan dalam meningkatkan mutu pelayanan menggunakan teori manajemen yang mutu pelayanan dengan 4 faktor yaitu, Planning/ Perencanaan, Organizing/ Pengorganisasian, Actuating/Pelaksanaan, Controlling/Pengawasan.

\subsection{Planning (Perencanaan)}

Perencanaan merupakan kegiatan menyusun konsep dan merumuskan kegiatan yang akan dilakukan sesuai dengan tujuan awal yang ditetapkan.

Rencana program dan kegiatan diorientasikan terhadap sasaran yang diharapkan dapat dicapai dalam periode 5 (lima) tahun mendatang. Rencana Program tersebut dapat diuraikan sebagai berikut :Program Pelayanan Administrasi Perkantoran, Program Peningkatan Saran dan Prasarana Aparatur, Program Peningkatan Disiplin Aparatur, Program Peningkatan Kapasitas Sumber Daya Aparatur, Program Peningkatan Pengembangan Sistem Pelaporan Capaian Kinerja dan Keuangan, Program Pengembangan Minat dan Budaya Baca Masyarakat, Program Pengembangan Perpustakaan, Program Perbaikan Sistem Administrasi Kearsipan, Program Penyelamatan dan Pelestarian Dokumen/Arsip Daerah, Program Pemeliharaan Rutin/Berkala Sarana dan Prasarana Kearsipan.

\subsection{Organizing (Pengorganisasian)}

Pengorganisasian dilaksanakan untuk mengumpulkan serta mengatur berbagai sumber daya yang dibutuhkan, diantaranya manusia, dengan demikian pekerjaan yang dimaksud dapat dilaksanakan dengan baik. 
Jurnal Politico Vol. 2 September 2018

Halaman 219-235. ISSN: p; 1829-6696, e:2549-4716

Web jurnal online; jurnal.unmuhjember.ac.id

Edhi Siswanto; Ika Herawati

UPAYA DINAS PERPUSTAKAAN DALAM MENINGKATKAN MUTU PELAYANAN

(studi Dinas Perpustakaan dan Kearsipan Kabupaten Jember)

\subsection{Actuating (Pelaksanaan)}

Pelaksanaan adalah ikhtiar untuk memotivasi anggota agar program-program dapat memperlihatkan hasilnya, berikut Program yang telah di laksanakan di Dinas Perpustakaan :

\subsubsection{Program Pengembangan Minat dan Budaya Baca Masyarakat}

Program ini merupakan program yang sangat penting demi mewujudkan visi Perpustakaan daerah yaitu terwujudnya Jember membaca, kemudian dalam upaya pencapaian program tersebut, Dinas perpustakaan melakukan beberapa kegiatan yaitu:

a. Penyedian Bantuan Pengembangan Perpustakaan Desa

Perpustakaan Desa merupakan Lembaga layanan publik yang ada di Desa. Pengembangan perpustakaan desa sangatlah penting untuk masyarakat sekitar desa, kegiatan ini juga merupakan salah satu upaya dinas perpustakaan dalam mempertahankan masyarakat untuk tetap gemar membaca karena perpustakaan desa sangat mudah untuk di jangkau, menurut poewadarminta kegiatan ini termasuk jenis upaya preservatif.

Penyediaan bantuan pengembangan perpustakaan Desa dari Dinas Perpustakaan belum bisa di realisasikan di tahun 2017 di karenakan terbentur waktu, penyediaan bantuan untuk perpustakaan desa memakan waktu yang cukup lama di karenakan masih harus proses pelelangan sehingga penyediaan bantuan ini akan di laksanakan di tahun 2018, selama ini perpustakaan Desa tetap di beri bantuan berupa Buku-buku dan Rak namun itu semua dari Pemerintah provinsi.

b. Pengembangan koleksi bahan pustaka perpustakaan umum Daerah

Pengembangan Koleksi bahan pustaka merupakan proses perencanaan untuk mendapatkan literature pustaka yang seimbang dengan banyak format termasuk buku, tabloid, literature online dan sumber-sumber media lainnya. Pengkayaan literature bahan pustaka di laksanakan dengan tujuan agar pemustaka dengan mudah menemukan buku-buku yang di inginkan. Menurut Sutarno N.S (2006) Pengembangan koleksi bahan pustaka memang perlu di kembangkan, karenasalah satu kriteria Perpustakaan di 
Jurnal Politico Vol. 2 September 2018

Halaman 219-235. ISSN: p; 1829-6696, e:2549-4716

Web jurnal online; jurnal.unmuhjember.ac.id

Edhi Siswanto; Ika Herawati

UPAYA DINAS PERPUSTAKAAN DALAM MENINGKATKAN MUTU PELAYANAN

(studi Dinas Perpustakaan dan Kearsipan Kabupaten Jember)

katakan baik jika perpustakaan memiliki koleksi yang dapat memenuhi kebutuhan informasi pemustakanya. Sama halnya dalam bantuan pengembangan perpustakaan desa kegiatan ini merupakan upaya preservatif karena Perpusda mempertahankan agar koleksi-koleksi perpustakaan terus berkembang. Berikut koleksi bahan pustaka di Dinas Perpustakaan dan Kearsipan Kabupaten Jember.

Tabel 4.3

Statistik Koleksi Tahun2017

\begin{tabular}{|c|c|c|c|}
\hline NO & Jenis Koleksi & Jumlah Judul & $\begin{array}{l}\text { Jumlah } \\
\text { Eksemplar/Keping }\end{array}$ \\
\hline 1 & Koleksi Buku & 30.909 & 91.663 \\
\hline 2 & Koleksi Majalah & 1.292 & 2.242 \\
\hline 3 & Koleksi Tabloid & 237 & 237 \\
\hline 4 & $\begin{array}{ll}\text { Koleksi Surat } \\
\text { Kabar }\end{array}$ & 351 & 12.238 \\
\hline 5 & Koleksi Buletin & 24 & 45 \\
\hline 6 & Koleksi Kaset CD & 298 & 791 \\
\hline \multicolumn{2}{|c|}{ Total } & 33.111 & 107.216 \\
\hline
\end{tabular}

Sumber : Data Statistik Koleksi Tahun 2017 Dinas Perpustakaan dan Kearsipan Kabupaten Jember 
Jurnal Politico Vol. 2 September 2018

Halaman 219-235. ISSN: p; 1829-6696, e:2549-4716

Web jurnal online; jurnal.unmuhjember.ac.id

Edhi Siswanto; Ika Herawati

UPAYA DINAS PERPUSTAKAAN DALAM MENINGKATKAN MUTU PELAYANAN

(studi Dinas Perpustakaan dan Kearsipan Kabupaten Jember)

c. Publikasi dan sosialisasi Minat dan Budaya Baca Masyarakat

Kegiatan publikasi dilaksanakan bertujuan untuk mempromosikan perpustakaan umum agar masyarakat dapat memanfaatkan fasilitas yang telah di berikan oleh pemerintah. Publikasi yang di maksud dengan melalui bazar buku, media sosial. Sedangkan Sosialisasi atau pengenalan program dimaksudkan agar masyarakat termotivasi untuk membudayakan gemar membaca. Program ini sebagai upaya Preventif memiliki konotatif negatif karena Perpusda berusaha mencegah masyarakat agar tidak malas membaca melalui kegiatan sosiasialisasi, perpusda mengajak masyarakat agar dapat meningkatkan gemar membaca, karena sifat malas membaca menyebabkan masyarakat ketinggalan informasi, memicu faktor kebodohan, rendahnya minat baca juga dapat mempengaruhi kualitas bangsa Indonesia.

d. Pengembangan dan Peningkatan Kreatifitas Pemustaka

Pengembangan dan Peningkatan Kreatifitas Pemustaka di laksanakan melalui Sekolah Literasi Gratis (SLG) yang di selenggarakan di Dinas Perpustakaan. SLG ini di ikuti hanya beberapa pemustaka. Perpustakaan mengundang para pemustaka yang ingin belajar menulis buku. Di SLG ini di ajarkan tata cara menulis sebuah buku yang baik dan nanti setelah buku selesai Dinas perpustakaan melaksanakan Bedah buku yang telah di tulis pemustaka, kegiatan ini di danai oleh APBD dan mendapatkan bantuan dari relawan, sebelumnya pada Tahun 2015 Perpusda membentuk kelas menulis (Writting class) sama halnya dengan SLG, Writtingclass juga mengajarkan tata cara menulis yang benar, pelatihan pembuatan proposal pengajuan naskah, namun kegiatan ini sudah lama tak aktiv sehingga Perpusda menggantinya dengan SLG,

\subsubsection{Program Pengembangan Perpustakaan}

Program pengembangan Perpustakaan itu wajib hukumnya dalam meningkatkan minat baca masyarakat dan pengembangan ini harus di lakukakan terus menerus dan berkelanjutanada beberapa kegiatan dalam menjaga Bahan Pustaka dan kegiatan tersebut merupakan upaya dalam mengembangkan perpustakaan yakni dengan melakukan kegiatan sebagai berikut: 
Jurnal Politico Vol. 2 September 2018

Halaman 219-235. ISSN: p; 1829-6696, e:2549-4716

Web jurnal online; jurnal.unmuhjember.ac.id

Edhi Siswanto; Ika Herawati

UPAYA DINAS PERPUSTAKAAN DALAM MENINGKATKAN MUTU PELAYANAN

(studi Dinas Perpustakaan dan Kearsipan Kabupaten Jember)

1. Preservasi bahan pustaka dan Konservasi bahan pustaka

A. Preservasi bahan pustaka

Preservasi merupakan kegiatan yang direncanakan dan dikelola untuk memastikan supaya literature perpustakaan bias di pakai dalam waktu yang lama, kegiatan ini dilakukan dengan cara :

a. Menjaga kelembaban suhu ruangan kurang lebih sekitar $26^{\circ}-29^{\circ}$ celcius, karena kerusakan bisa terjadi akibat kelembaban udara

b. Melakukan penataan buku sesuai dengan prosedure yaitu:

-Buku harus tegak di Rak

-Menyisakan beberapa inci ruang kosong di setiap rak

B. Konservasi Bahan Pustaka

Sedangkan Konservasi merupakan suatu kegiatan perlindungan dan pemeliharaan secara teratur untuk mencegah kerusakan bahan pustaka, semua koleksi perpustakaan perlu di pelihara dan di lestarikan dengan baik, dalam hal ini Dinas Perpustakaan dan Kearsipan Kabupaten Jember mengadakan Fumigasi yang di laksanakan selama satu tahun sekali. Fumigasi dapat dilakukan melalui Teknik pengasapan, yaitu dengan menyemprotkan gas zat metelbromide $(\mathrm{Ch} 3 \mathrm{Br})$ cair kedalam ruang koleksi yang di tutup lebih dahulu. Perpusda menggunakan cara ini karena waktu yang di butuhkan hanya 24 Jam, dan kegiatan ini dilaksanakan bergantian dengan bidang kearsipan ,Jadi di hari Fumigasi tersebut layanan Perpustakaan di tutup selama 1 hari,.

\section{Meningkatkan Kualitas Jasa Layanan Perpustakaan}

Pelayanan merupakan ujung tombak dari semua kegiatan perpustakaan, karena citra perpustakaan di lihat dari kegiatan layanan yang di berikan kepada pemustaka, Menurut a.s moenir terdapat beberapa unsur yang mendukung jalannya kegiatan layanan

\section{A. Personil}


Jurnal Politico Vol. 2 September 2018

Halaman 219-235. ISSN: p; 1829-6696, e:2549-4716

Web jurnal online; jurnal.unmuhjember.ac.id

Edhi Siswanto; Ika Herawati

UPAYA DINAS PERPUSTAKAAN DALAM MENINGKATKAN MUTU PELAYANAN

(studi Dinas Perpustakaan dan Kearsipan Kabupaten Jember)

Paling utama adalah perilaku aparatur, aparatur pelayanan publik pemerintah haruslah profesional, disiplin dan terbuka dalam kritik dan saran, dalam hal ini menurut pengamatan peneliti aparatur dinas perpustakaan dan kearsipan khususnya bidang perpustakaan kurang disiplin dan kurang profesional, ada beberapa staff yang keluar di jam kerja, tidak adanya kotak kritik dan saran sehingga pemusta atau pengunjung susah dalam mengapresiasikan pendapatnya tentang pelayanan yang di berikan kepada pemustaka

\section{B. Sarana dan Prasarana}

Dibutuhkan prasarana serta tempat kerja untuk fasilitas pelayanan publik, menurut pengamatan peneliti sarana dan prasarana baik untuk ruang kerja aparatur maupun fasilitas dalam kegiatan pelayanan publik sudah cukup lengkap

C. Masyarakat sebagai pelanggan

Masyarakat sebagai pelanggan heterogen tingkat pendidikan maupun perilaku, dalam hal ini dinas perpustakaan menggunakan unsur tersebut, pengunjung atau pemustaka yang tidak dapat menemukan buku dapat meminta bantuan kepada staff layanan.

\subsection{Controlling (Pengawasan)}

Controlling/pengawasan adalah penemuan serta penerapan dan sarana untuk menjamin bahwasannya rencana dilakukan merujuk pada rencana yang telah ditetapkan. Berikut Standar Oprasional Prosedure (SOP) pada Dinas Perpustakaan Kabupaten Jember :

1). SOP Pembuatan Kartu Tanda Anggota

2). SOP Peminjaman Buku Koleksi

3). SOP Pengembalian Buku Koleksi

Namun SOP tersebut belum di perbarui sampai sekarang, dan menurut pengamatan peneliti ada beberapa prosedur yang tidak sesuai dengan SOP. Sop layanan perpustakaan juga tidak transparan, hal ini menyebabkan hal tersebut peneliti meminta 
Jurnal Politico Vol. 2 September 2018

Halaman 219-235. ISSN: p; 1829-6696, e:2549-4716

Web jurnal online; jurnal.unmuhjember.ac.id

Edhi Siswanto; Ika Herawati

UPAYA DINAS PERPUSTAKAAN DALAM MENINGKATKAN MUTU PELAYANAN

(studi Dinas Perpustakaan dan Kearsipan Kabupaten Jember)

SOP tersebut kepada sekretariatan Dinas Perpustakaan dan Kearsipan Kabupaten Jember

\section{B. Deskripsi tentang Hambatan yang di hadapi Perpusda dalam menngkatkan Mutu Pelayanan}

\section{Masih terbatasnya kualitas Sumber Daya Manusia (SDM)}

SDM dapat di ukur melalui kualitas Pengetahuan, Kurangnya mutu Sumber Daya Manusia sangat berpengaruh terhadap mutu pelayanan yang di berikan kepada pengguna perpustakaan, Faktanya kualitas Sum ber Daya Manusia di Perpustakaan Kabuapaten Jember sangat memprihatinkan. Sumber Daya Manusia di Perpustakaan Daerah Kabupaten Jember jauh dari kata berkualitas karena untuk salah satu pustakawannya sendiri belum termasuk pustakawan yang mempunyai kompetensi, belum diakui oleh badan standarisasi nasional sehingga sangat kesulitan dalam mengimplementasikan program, dalam proses penerimaan pegawai juga tidak ada penyeleksian,

\section{Kondisi Sarana dan Prasarana}

Faktor penghambat lain menurut pengamatan peneliti yaitu sarana dan prasarananya, seperti yang sudah di paparkan sebelumnya sarana prasarana Perpusda sudah cukup lengkap namun semua itu belum membuat pengunjung tertarik karena kondisi ruangan perpusda yang gelap atau redup dan tidak sejuk terutama pada ruang baca novel, pada ruang baca anak juga tidak ada slogan-slogan atau hiasan dinding sedangkan menurut peneliti hal itu perlu di lakukan, hiasan atau slogan sangat di perlukan agar pengunjung anak-anak tertarik dan nyaman membaca di perpusda, selain kondisi ruangan. 
Jurnal Politico Vol. 2 September 2018

Halaman 219-235. ISSN: p; 1829-6696, e:2549-4716

Web jurnal online; jurnal.unmuhjember.ac.id

Edhi Siswanto; Ika Herawati

UPAYA DINAS PERPUSTAKAAN DALAM MENINGKATKAN MUTU PELAYANAN

(studi Dinas Perpustakaan dan Kearsipan Kabupaten Jember)

\section{PENUTUP}

\section{Kesimpulan}

Upaya Dinas Perpustakaan dalam meningkatkan mutu pelayanan dapat di ukur melalui 4 faktor yaitu :Planning (Perencanaan), Organizing (Pengorganisasian), Actuating (Pelaksanaan), Controlling (Pengawasan).pada Renja 2017 Dinas perpustakaan melaksanakan beberapa program. Berikut program dan kegiatan-kegiatan yang berhubungan dangan bidang Perpustakaan Kabupaten Jember, yakni :
a. Penyedian Bantuan Pengembangan Perpustakaan Desa
b. Pengembangan koleksi bahan pustaka
c. Sosialisasi dan publikasi minat dan budaya membaca masyarakat
d. Pengembangan dan Kreatifitas Pemustaka
e. Preservasi bahan Pustaka
f. bahan pustaka

Ada beberapa hambatan yang di alami Dinas Perpustakaan dalam meningkatkan minat baca masyarakat, yakni sebagai berikut :

\section{Terbatasnya Mutu Sumber Daya Manusia}

Sumber Daya Manusia di Perpustakaan Daerah Kabupaten Jember jauh dari kata berkualitas dilihat dari salah satu pustakawan yang tidak kompeten, dan juga tidak adanya diklat dan BIMTEK untuk semua aparatur

\section{.2. Sarana dan Prasarana}

Alat dan Peralatan di Perpustakaan terbilang memang cukup lengkap namun kondisi ruangan yang redup, kerusakan mesin cetak KTA yang lama, ruang audiovisual yang kurang kondusif berdampak pada kurangnya minat masyarakat untuk berkunjung di Perpustakaan Daerah. 
Jurnal Politico Vol. 2 September 2018

Halaman 219-235. ISSN: p; 1829-6696, e:2549-4716

Web jurnal online; jurnal.unmuhjember.ac.id Edhi Siswanto; Ika Herawati

UPAYA DINAS PERPUSTAKAAN DALAM MENINGKATKAN MUTU PELAYANAN

(studi Dinas Perpustakaan dan Kearsipan Kabupaten Jember)

\section{Saran}

Dari hasil analisis serta penelitian di lapangan terhadap Upaya Dinas Perpustakaan dalam Meningkatkan Mutu Pelayanan, penulis dapat menyusun saran berikut ini. Di harapkan pemerintah pusat bisa menyediakan bantuan biaya pendidikan S1 Ilmu Perpustakaan dengan harapan nantinya banyak tersedia SDM bermutu di bidang perpustakaan. Sangat perlu adanya peran pemerintah pusat maupun pemerintah didaerah dalam hal mendorong usaha peningkatan minat baca masyarakat. 
Jurnal Politico Vol. 2 September 2018

Halaman 219-235. ISSN: p; 1829-6696, e:2549-4716

Web jurnal online; jurnal.unmuhjember.ac.id

Edhi Siswanto; Ika Herawati

UPAYA DINAS PERPUSTAKAAN DALAM MENINGKATKAN MUTU PELAYANAN

(studi Dinas Perpustakaan dan Kearsipan Kabupaten Jember)

\section{DAFTAR PUSTAKA}

Iskandar. 2016. Manajemen dan Budaya Perpustakaan. Bandung: Refika Aditama.

Mulyadi Deddy. 2016. Studi Kebijakan Publik dan Pelayanan Publik. Bandung: Alfabeta

Hardiyansyah. 2011. Kualitas Pelayanan Publik, konsep, Dimensi, Indikator, dan Implementasinya. Gava media, Yogyakarta

Sutarno. 2003. Perpustakaan dan Masyarakat. Jakarta: Yayasan Obor Indonesia.

Sulistiyo-basuki. 1991. Pengantar Ilmu Perpustakaan. Jakarta: Gramedia Pustaka Utama

Moleong. 2007. Metode Penelitian Kualitatif. Bandung: Remaja Rosdakarya

\section{Dokumen-dokumen}

Undang-undang No. 43 Tahun 2007 tentang perpustakaan

Peraturan Bupati No. 52 Tahun 2016 tentang kedudukan, susunan organisasi, tugas dan fungsi serta tata kerja Dinas Perpustakaan dan Kearsipan Kabupaten Jember

RENJA Tahun 2017 Dinas Perpustakaan dan Kearsipan Kabupaten Jember

RENSTRA Tahun 2016-2021 Dinas Perpustakaan dan Kearsipan Kabupaten Jember

\section{Sumber Internet}

Rahman. Fadilah, (2013). Upaya Kantor Perpustakaan dan Arsip Kabupaten Paser dalam meningkatkan minat membaca masyarakat di perpustakaan umum Kabupaten Paser. E-Joernal. Ilmu Administrasi Negara http://ejournal.an.fisipunmul.ac.id/site/wp-content/uploads/2013/08/E-JOURNAL\%20(08-05-13-02-4712).pdf

http://blog.alimsumarno.com/perbedaan-penelitian-dan-pengembangan

http://bphm.unila.ac.id/images/bphm/doc/UU-No-25-Thn-2009-ttg-Pelayanan-

Publik.pdf 